\title{
Anomalous Gene Expression in Alzheimer Disease: Cause or Effect
}

\author{
D.R.C. McLachlan, W.J. Lukiw, C. Mizzen, M.E. Percy, M.J. Somerville, \\ M.K. Sutherland and L. Wong
}

\begin{abstract}
Altered chromatin conformation and increased amounts of aluminum have been observed in the brains of patients with Alzheimer disease. These factors have been shown to affect gene regulation. In this report, we describe how these changes may selectively alter the pool size of the human light chain neurofilament gene and play a fundamental role in the expression of this disease.
\end{abstract}

RÉSUMÉ: Expression génique anormale dans la maladie d'Alzheimer : cause ou effet? Une conformation altérée de la chromatine et une augmentation de la quantité d'aluminium ont été observées dans le cerveau de patients atteints de la maladie d'Alzheimer. Il a été démontré que ces facteurs affectent la régulation génique. Dans cet article, nous décrivons comment ces changements peuvent modifier sélectivement la taille du pool du gène humain codant la chaîne légère du neurofilament et jouer un rôle fondament dans l'expression de cette maladie.

Can.J. Neurol. Sci. 1991; 18: 414-418

\section{The Neuropathology of Alzheimer Disease}

Despite world-wide research efforts, Alzheimer disease (AD) remains a major health problem of the elderly and no treatment or prevention for it has been devised. However, considerable progress has been made in characterizing the brain tissue changes associated with the disease.

Two histopathological hallmarks of AD have been intensively investigated: amyloid in "senile" plaques, and neurofibrillary tangles. The purification and sequencing of amyloid, a protein which is found in the cores of senile plaques, was achieved by Glenner and Wong,' and the sequence for the gene coding for the amyloid precursor protein (APP) was reported by Kang et al. ${ }^{2}$ APP is a glycoprotein which spans the plasma membrane; it has been identified in a variety of different animal species and cell lines. Alternate forms of APP exist (for example, APP751 contains a sequence homologous to the Kunitz serine protease inhibitor) but the significance of this heterogeneity is not known. Recent evidence suggests that normally APP is cleaved within the amyloid portion of the peptide by APP secretase. Esch et al. ${ }^{3}$ speculate that amyloid formation in AD results from down-regulation of this enzyme. An alternate hypothesis is that deposits of silicon and aluminum identified in the cores of the senile plaques ${ }^{4}$ somehow "seed" amyloid deposition. ${ }^{5}$ Studies with antibodies to native amyloid suggest that nonfilamentous "preamyloid" deposits precede the appearance of the senile plaques. ${ }^{6}$

The mechanisms responsible for the assembly of the neurofibrillary tangles (NFT) are not as well understood. Wischik et al. ${ }^{7}$ have postulated that the formation of a polymer from a fragment with microtubule binding sites of the microtubule associated protein tau, and another not-yet-identified protein, is the first step in NFT formation. Abnormally phosphorylated tau and ubiquitin, a molecule that tags proteins for intracellular degradation, have been identified in NFT. ${ }^{8}$ Abnormal phosphorylation is thought to be one of the earliest events in neurofibrillary pathology and to precede the ubiquitination. Tau is normally found in axons; the abnormal presence of tau in nerve cell bodies and in dystrophic neurites in AD may be the result of aberrant transport from the ribosomal to the axonal compartments. ${ }^{9}$ High concentrations of aluminum have also been found in NFT using two different analytical methods, 10,11 but the relationship of aluminum accumulation to other histopathological features is not known.

Unfortunately, intensive investigation of the pathological changes in $\mathrm{AD}$ has not revealed the cause of the disease. Indeed, the neuropathological changes may not be closely linked to the cause and alternate investigative approaches are therefore justified.

Our group has been studying gene expression in AD by analyzing chromatin structure, and quantitatively determining the pool sizes of various messenger RNAs. Our observations indicate that change in chromatin structure and the down-regulation of at least one neuron-specific gene, are associated with the Alzheimer process. In this paper, we summarize our data to date, and comment on the relevance of these findings.

From the Centre for Research in Neurodegenerative Disease, University of Toronto (D.R.C.M., W.J.L, C.M., M.K.S., L.W.) and the Department of Genetics, Surrey Place Centre (M.E.P., M.J.S.), Toronto, Canada M5S 2C2

Reprint requests to: D.R.C. McLachlan, Centre for Research in Neurodegenerative Disease, University of Toronto, Toronto, Canada M5S 1A8 


\section{Evidence for Altered Chromatin Structure in AD}

The particular alterations in chromatin structure found in AD do not occur in 12 other neurodegenerative diseases; these are listed below. Our observations have been based upon analysis of 85 AD-affected, 60 healthy, 49 non-AD dementia-associated human brains, and scrapie-induced changes in mouse brain. ${ }^{12-14}$

1) Nuclear contents derived from AD-affected neocortex have an increased resistance to shearing by sonication. In neocortical gray matter from control individuals, $25 \%$ of the DNA is in a heavy heterochromatized fraction compared to $54 \%$ in AD-affected neocortex. ${ }^{15}$

2) DNA from AD-affected neocortex is less susceptible to digestion with several nucleases (micrococcal nuclease (MN), Aval or DNase I). This is reflected by a reduced yield of mononucleosomes in comparison with dinucleosomes and larger oligomers. ${ }^{15}$

3) Compared to control preparations, MN-released dinucleosomes from AD-affected neocortex exhibit 3 important differences: (i) There is an increase in the proportion of linker histone $\mathrm{Hl}^{\circ}$ (the $\mathrm{H} 1^{\circ} / \mathrm{H} 4$ ratio is increased by $210 \%$ ); 13,16 (ii) They contain a group of non-histone proteins of about 41 $\mathrm{kDa}{ }^{15}$ and, (iii) The aluminum/DNA ratio is increased 5 to 9-fold [unpublished].

4) We have demonstrated an alteration in linker histone-DNA binding in $\mathrm{AD}$ and in the presence of aluminum salts in vitro. 17,18

5) The $\mathrm{HI}^{\circ}$-associated dinucleosomes are enriched in the gene for the low molecular weight neurofilament, HNF-L. 19 This was shown by lightly digesting nuclei from neocortex with $\mathrm{MN}$, separating the mononucleosomes from the di-/tri-nucleosome and polysome fractions, and measuring the hybridization signal in each with the HNF-L promoter region (which includes sequences involved in the binding of RNA polymerase II and other regulatory components of gene transcription) as a probe, using Southern blot analysis. ${ }^{15}$ In control preparations, $46.1 \%$ of the total hybridizable signal was associated with the mononucleosome fraction and $7.7 \%$ with the di- and tri-nucleosome fraction. In AD preparations, only $7 \%$ of the total hybridizable signal was in the mononucleosome fraction, while the di- and tri-nucleosome fraction contained $37.8 \%$ of the total signal. In contrast, $94 \%$ of the total signal was associated with the polysome fraction when a probe for $\gamma$-crystallin (a single copy gene not expressed in brain) was employed. Similar results were obtained using the endonuclease Aval in place of MN. ${ }^{15}$ Using probes for different regions of the HNF-L gene, we have now shown that at least $3.5 \mathrm{~kb}$ of the HNF-L gene is predominantly associated with the $\mathrm{Hl}^{\circ}$ enriched, di-/trinucleosome (i.e., heterochromatized) fraction in AD. Studies by others have shown that mononucleosomes released by light $\mathrm{MN}$ digestion contain chromatin in transcriptionally competent conformation. Our finding of a 5 -fold reduction in the amount of DNA containing the promoter region of the HNF-L gene in a mononucleosome fraction and a corresponding increase in the dinucleosome fraction enriched in $\mathrm{H}^{\circ}$ in $\mathrm{AD}$-affected superior temporal cortex, suggests that changes in neuronal chromatin conformation occur in AD that affect at least one functionally important gene, HNF-L. If the hybridizable HNF-L signal in the mononucleosome and di-/tri-nucleosome fractions is derived from neurons, and the mononucleosomes and di-/trinucleosomes contain chromatin domains that are transcriptionally active and inactive, respectively, then one interpretation for our data is that about $15 \%$ (i.e., $7 / 7+37.8 \times 100$ ) of neuronal DNA is transcriptionally active in AD.

There is evidence that during normal development, the linker histone protein $\mathrm{H}^{\circ}$ specifically shuts off the transcription of certain genes, although the molecular process that is involved is unknown. ${ }^{20-22}$ We have recently addressed the critical question of whether the HNF-L promoter region is actually bound to $\mathrm{H}^{\circ}$ in AD brain. We prepared an antibody to avian $\mathrm{H} 5$; in Western blots this reacted only with human $\mathrm{H}^{\circ}$. This was coupled to Sepharose and used to isolate $\mathrm{H} 1^{\circ}$ containing nucleosomes. Based upon the average of $4 \mathrm{AD}$ preparations, $\mathrm{HI}^{\circ}$ containing mono- and di-nucleosomes contained 1.75 times more HNF-L promoter sequence per unit of DNA than preparations from 4 non-AD age and agonal process related control brains. In contrast, the ratio for human prion (Pr22) was 1.08 , and that for calbindin-27D (CaBP27) was 0.99 [unpublished].

\section{Messenger RNA Pool Size}

The inability of both MN (a small protein of $17 \mathrm{kDa}$ ) and Ava I (a larger protein of $78 \mathrm{kDa}$ ) to access the HNF-L locus in AD brain raises the possibility that access by the large multi-subunit complex of RNA polymerase II (about $500 \mathrm{kDa}$ ) to DNA sequences important in the initiation of transcription might be impaired in AD. This hypothesis predicts that there should be a disorder in transcription in $\mathrm{AD}$ and, in keeping with our preceding observation, a reduced mRNA pool size for HNF-L.

Accordingly, we have measured the relative abundances of mRNAs coding for several proteins by quantitative dot-blot analysis. The results are summarized in Table 1. Importantly, the mRNA pool size of HNF-L in AD is reduced to about $27 \%$ of that for age-matched, non-AD neocortex (control preparations). The reduction is considerably greater than can be accounted for by neuron loss alone. In contrast, there was no reduction for prion mRNA which is expressed predominantly in neurons, ${ }^{23}$ or in certain other mRNAs ( $\beta$-actin, calbindin-27, tau and gap 43).

Table 1. Relative amounts of specific messenger RNA in temporal neocortex of patients with Alzheimer disease compared to individuals with non-Alzheimer dementia determined by quantitative dotblot analysis. Analysis of Variance (ANOVA) $=P$ value.

\begin{tabular}{lclr}
\hline & $\begin{array}{c}\text { Percent Ratio } \\
\text { AD/C }\end{array}$ & P value & n: AD/C \\
HNF-L & 27 & & \\
calpain I & 67 & 0.0001 & $10 / 12$ \\
$\propto$-tubulin & 58 & 0.02 & $6 / 8$ \\
$\beta$-actin & 108 & 0.01 & $10 / 12$ \\
calbindin & 100 & n.s. & $10 / 12$ \\
tau & 89 & n.s. & $5 / 3$ \\
\hline
\end{tabular}

Post mortem tissue from the temporal neocortex was obtained from subjects with Alzheimer disease (AD) and non-AD dementia (C) matched for age, agonal duration and post mortem interval. Total RNA was extracted and the mean value of specific messenger RNAs in the tissue was determined for each group using quantitative dot blot analysis. 200 $\mu \mathrm{l}$ aliquots containing 1.0, 2.5 and $3.5 \mu \mathrm{g}$ of total RNA were spotted and dried on $0.2 \mu \mathrm{m}$ Biotrans membrane in a BRL Hybridot manifold, and hybridized with specific probes as described by McLachlan et al. ${ }^{14}$ 
A reduction in mRNA coding for HNF-L in AD also has been reported by other laboratories. 24,25

We have also demonstrated a statistically significant selective reduction of HNF-L in AD compared to age, agonal-status, and post-mortem interval matched controls in single neurons in the $\mathrm{CA} 1$ and $\mathrm{CA} 2$ regions of the hippocampus ${ }^{26}$ and in pyramidal neurons of layers III and V of the temporal cortex ${ }^{27}$ by in situ hybridization. Although an AD-associated reduction of polysomal mRNA translation has been described, ${ }^{28}$ we have obtained no evidence to suggest that the reduction in HNF-L mRNA pool size is due to either a general, ${ }^{29}$ or selective increase ${ }^{26,30}$ in the degradation of mRNA.

A frequency distribution of the amount of HNF-L message per square micron in layer $\mathrm{V}$ of the mid-temporal gyrus in AD and control brains is given in Figure 1 . These data suggest that all of the neurons in this brain region are affected. If they were not, the frequency distribution in AD should be biphasic and a small percentage of neurons should exhibit control mRNA pool sizes. Any model which might explain our findings in AD must account for this observation.

It has been suggested that alterations in gene expression in AD may reflect an attempt by neurons to regenerate. This is not supported by the data in Table 1 . The pattern of mRNA pool sizes observed in AD for the cytoskeletal genes is distinctly different from that seen during axotomy or during differentiation. ${ }^{38,39}$ The mRNA pool size for HNF-L is reduced in AD, and that for actin, tau and Gap 43 is not different from controls. Our chromatin and mRNA studies collectively support the idea that

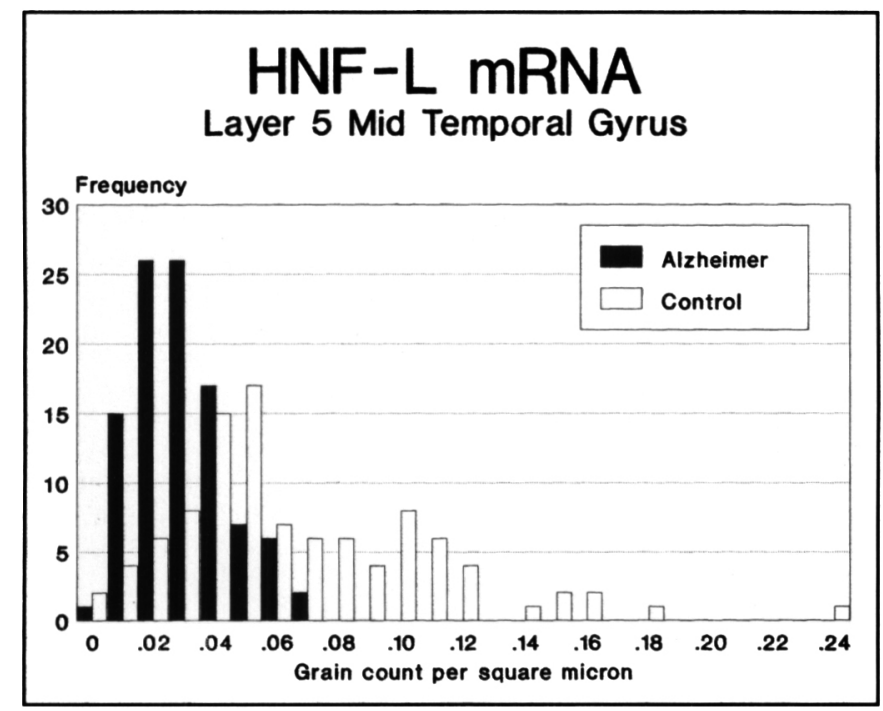

Figure 1 - Frequency distribution of the amount of $H N F-L$ messenger RNA per square micron in pyramidal neurons of the middle temporal gyrus of Alzheimer patients and control individuals.

HNF-L MRNA was revealed in individual neurons by tissue in situ hybridization with a tritium-labelled probe as described by Somerville et al. ${ }^{26}$ The number of grains corresponding to HNF-L message in each neuron, and the area of each was determined using quantitative image analysis. Sections from 4 pairs of Alzheimer patients and control individuals (in this case Huntington disease patients with clinical dementia) matched for age (range 60-65 years), agonal process, and post mortem interval (range 2-10 hours) were examined. One hundred cells were examined in each group. The frequency distributions of the grain count (with background subtracted) per square micron for individual neurons for each group are shown.
HNF-L is a prime target in AD and that normal gene regulation for at least this one neuron-specific gene is aberrant.

We speculate that the down-regulation of HNF-L could lead to the generation of neurofibrillary tangles in the following way. Tau, a protein which facilitates microtubule assembly and is thought to cross-link microtubules to HNF-L, ${ }^{31}$ does not exhibit a reduction in mRNA pool size. ${ }^{32}$ Moreover, it is one of the core proteins found in the paired helical filaments of NFT. Perhaps the assembly of tau into insoluble paired helical filaments is a compensatory response to a disorder in gene expression which fails to reduce tau transcription in tandem with HNF-L.

We question whether such neurofibrillary degeneration is causally related to disturbances in the information processing function of neurons. Young Chamorro adults on Guam who die of non-neurological disorders, may have extensive brain neurofibrillary degeneration, but no neurological signs or symptoms.

Regardless of the functional significance of NFT, the decrease in mRNA pool size for HNF-L may be responsible, at least in part, for the consistent finding that dendrites and neuron cell bodies are smaller in AD-affected than control brains,since neurofilaments are structural elements which contribute to neurite volume. However, we have found no significant correlation between cell size and HNF-L mRNA amount in our in situ hybridization studies. ${ }^{26,27}$ It may also underlie the intriguing observation that in layer II pyramidal neurons of the parahippocampal gyrus, the apical dendrites in AD are considerably shorter in length than in age-matched controls and do not show the lengthening with age seen in healthy control brains. ${ }^{33}$ The latter observations suggest that surviving neurons in $A D$ are unable to undergo neurite extension to expand dendritic fields in response to neuron loss.

\section{A Unifying Model for Altered Gene Expression in AD}

Our data strongly suggest that the linker histone, $\mathrm{HI}^{\circ}$, is intimately involved in the regulation of HNF- L transcription, but the mechanism for repression is not known. Among the possibilities are:

1) Post-translational modifications of $\mathrm{Hl}^{\circ}$ increase its probability of binding to DNA.

2) An altered concentration of a trans-acting factor such as a non-histone DNA binding protein somehow signals the anomalous docking of $\mathrm{H}^{\circ}$ to a specific gene sequence. ${ }^{34}$

3) A DNA concensus sequence in some genes is recognized by an $\mathrm{H}^{\circ}$ sub-species. ${ }^{35}$ We have identified a consensus sequence in the promoter region of HNF-L.

4) In vitro and in vivo effects of aluminum on chromatin conformation are well-documented. 17,36 Further, aluminum reduces NF-L pool size in rabbit spinal cord. ${ }^{37}$ An abnormal aluminum ion concentration may stabilize linker histone $\mathrm{H}^{\circ}$ binding to the NF-L locus in particular. (Perhaps replacement of magnesium by aluminum at critical sites in euchromatin, results in the formation of a coordination complex between aluminum, asp 98 and glu 99 of $\mathrm{H}^{\circ}$, and DNA. Because aluminum has a higher charge and smaller ionic radius than magnesium, aluminum binding at such a site would be expected to increase the relaxation time, but not necessarily prevent complete transcription.) We postulate that in normal chromatin, the HNF-L gene promoter oscillates between a condensed $\mathrm{HI}^{\circ}$-associated non-transcribable form, and an 
open transcribable form that is $\mathrm{H} 1^{\circ}$-free. In $\mathrm{AD}$, the former state is more probable and would result in reduced production of HNF-L mRNA. Such a mechanism would account for our finding that by in situ hybridization analysis, all neurons in AD-affected cortex are down-regulated, but that with micrococcal nuclease digestion, approximately $15 \%$ of DNA is in a conformationally active state.

\section{Are the Changes in Gene Expression a Cause or an Effect in AD?}

While the aluminum or other models may explain how genespecific reduced expression may occur in $\mathrm{AD}$, these shed no light on whether reduced transcription is a cause or an effect. At present it is difficult to address this dilemma directly. Our work with changes in chromatin structure and quantitation of mRNA pool sizes has been made for the most part, on AD-affected cortex, and it may not be legitimate to assume that changes are similar in all affected areas. Although we have argued that our observed mRNA changes do not appear to be secondary to a model analogous to axotomy, ${ }^{38,39}$ or to a repair response with neurite extension, ${ }^{40}$ our analyses have not been comprehensive, and were not applied to single cells in all cases. We also cannot exclude the possibility that the changes we have observed are a response to a particular type of stress, or related to loss of a putative growth factor from target neurons. Nevertheless, our data do not contradict the hypothesis that the primary etiological event in $\mathrm{AD}$ operates at the level of gene transcription. Because of increasing evidence that increased aluminum exposure might be a significant risk factor for $\mathrm{AD}$, in our opinion, elucidation of the mechanism for down-regulation of neuron-specific genes in Alzheimer disease, and the possible connection with aluminum, are exciting avenues that must be further explored.

\section{ACKNOWLEDGEMENTS}

This work was supported in part by grants from the Medical Research Council of Canada, Ontario Mental Health Foundation, the Ministry of Community and Social Services Lottery Grants Programme and the Scottish Rite Charitable Foundation.

\section{REFERENCES}

1. Glenner GG, Wong CW. Alzheimer's disease: Initial report of the purification and characterization of a novel cerebrovascular amyloid protein. Biochem Biophys Res Comm 1984; 120: 885-890.

2. Kang J, Lemaire HG, Unterbeck, et al. The precursor of Alzheimer's disease amyloid A4 protein resembles a cell-surface receptor. Nature 1987; 326: 733-736.

3. Esch FE, Keim PS, Beattie EC, et al. Cleavage of amyloid $\beta$ peptide during constitutive processing of its precursor. Science 1990; 248: 1122-1124.

4. Candy JM, Klinowski J, Perry RH, et al. Aluminosilicates and senile plaque formation in Alzheimer's disease. Lancet 1986; 1: 354-357.

5. Edwardson JA, Candy JM. Aluminum and the aetiopathogenesis of Alzheimer's disease. Neurobiol Aging 1990; 11: 314.

6. Selkoe DJ. Deciphering Alzheimer's disease: The amyloid precursor protein yields new clues. Science 1990; 248: 1058-1060.

7. Wischik CM, Novak M, Bondareff W, et al. Molecular dissection of Alzheimer Pathology. In: Miyatake T, Selkoe DJ, Ihara Y, eds. Molecular Biology and Genetics of Alzheimer's Disease, International Congress Series. Amsterdam: Elsevier Science Publishers B.V. 1990; 884: 47-56.

8. Iqbal K, Grundke-Iqbal I. Cytoskeletal protein pathology in Alzheimer's disease: Protein phosphorylation and ubiquitination. In: Miyatake T, Selkoe DJ, Ihara Y, eds. Molecular Biology and
Genetics of Alzheimer's Disease, International Congress Series. Amsterdam: Elsevier Science Publishers B.V. 1990; 884: 47-56.

9. Kosik KS. The neuritic dystrophy of Alzheimer's disease. In: Miyatake T, Selkoe DJ, Ihara, eds. Molecular Biology and Genetics of Alzheimer's Disease, International Congress Series. Amsterdam: Elsevier Science Publishers B.V. 1990; 884: 37-45.

10. Perl DP, Brody AR. Alzheimer's disease: X-ray spectrometric evidence of aluminum accumulation in neurofibrillary tangle-bearing neurons. Science 1980; 208: 297-299.

11. Perl DP, Pendlebury WW. Aluminum accumulation in neurofibrillary tangle-bearing neurons of senile dementia. Alzheimer's type: Detection by intraneuronal X-ray spectrometry studies of unstained tissue sections. J Neuropathol Exp Neurol 1984; 43: 349.

12. Crapper DR, Quittkat S, De Boni U. Altered chromatin conformation in Alzheimer's disease. Brain 1979; 102: 483-495.

13. McLachlan DR, Lewis PN, Lukiw WJ, et al. Chromatin structure in dementia. Ann Neurol 1984; 15: 329-334.

14. McLachlan DR Crapper, Lukiw WJ, Cho HJ, et al. Chromatin structure in scrapie and Alzheimer's disease. Proceedings of the First Canadian Symposium on the Organic Dementias, London, June 1986. Can J Neurol Sci 1986; 13: 427-431.

15. Lukiw WJ, McLachlan DRC. Chromatin structure and gene expression in Alzheimer's disease. Mol Brain Res 1990; 7: 727-734.

16. Lewis PN, Lukiw WJ, De Boni J, et al. Changes in chromatin structure associated with Alzheimer's disease. J Neurochem 1981; 37 : 1193-1202.

17. Lukiw WJ, Kruck TPA, McLachlan DR Crapper. Alternations in human linker histone-DNA binding in the presence of aluminum salts in vitro and in Alzheimer's disease. Neurotoxicology 1987; 8: 291-302.

18. Lukiw WJ, Kruck TPA, McLachlan DR. Linker histone-DNA complexes: Enhanced stability in the presence of aluminum lactate and implications for Alzheimer's disease. FEBS Lett 1989; 253: $59-62$.

19. Somerville MJ, McLachlan DR, Percy ME. Localization of the human 68,000 dalton human neurofilament gene (NF68) using a murine cDNA probe. Genome 1988; 30: 499-500.

20. Medvedev ZA, Medvedev MN, Robson L. Tissue specificity and age changes of the pattern of the $\mathrm{Hl}$ group of histones in chromatin from mouse tissues. Gerontology 1978; 24: 286-292.

21. Pehrson J, Cole RD. Histone $\mathrm{H}^{\circ}$ accumulates in growth inhibited cultured cells. Nature 1980; 285: 43-53.

22. Roche J, Gorka CL, Goeltz P, Lawrence JJ. Association of histone $\mathrm{H}^{\circ}$ with a gene repressed during liver development. Nature 1985; 314: 197-198.

23. Kretzschmar HA, Prusiner SB, Stowring MS, DeArmond SJ. Scrapie prion proteins are synthesized in neurons. Am J Pathol 1986; 122: 1-5.

24. Kittur S, Hoh J,Kawas C, et al. Neurofilament gene expression in Alzheimer's disease. Neurobiol Aging 1990; 11: 285-286.

25. Clark AW, Krekoski CA, Parhad IM, et al. Altered expression of genes for amyloid and cytoskeletal proteins in Alzheimer cortex. Ann Neurol 1989; 25: 331-339.

26. Somerville MJ, Percy ME, Bergeron $\mathrm{C}$, et al. Localization and quantitation of $68 \mathrm{kDa}$ neurofilament and superoxide dismutase- 1 mRNA in Alzheimer brains. Mol Brain Res 1991; 9: 1-8.

27. Somerville MJ, Bergeron C, Yoong LKK, et al. Neuronal expression of the light chain neurofilament and superoxide dismutase- 1 genes in the temporal lobe of Alzheimer brains. In: Iqbal K, McLachlan DRC, Winblad W, Wisniewski, eds. Alzheimer's Disease: Basic Mechanisms, Diagnosis and Therapeutic Strategies. Sussex: John Wiley \& Sons Ltd, 1991: 237-242.

28. Langstrom NS, Anderson JP, Lindroos HG, et al. Alzheimer's disease-associated reduction of polysomal mRNA translation. Mol Brain Res 1989; 5: 259-269.

29. Guillemette JG, Wong L, McLachlan DRC, et al. Characterization of messenger RNA from the cerebral cortex of control and Alzheimer-afflicted brain. J Neurochem 1986; 47: 987-997.

30. Lukiw WJ, Wong L, McLachlan DR. Cytoskeletal messenger RNA stability in human neocortex: studies in normal aging and in Alzheimer's disease. Int J Neurosci 1990; 55: 81-88. 
31. Heimann R, Shelanski ML, Liem RKH. Microtubule-associated proteins bind specifically to the $70-\mathrm{kDa}$ neurofilament protein. $\mathrm{J}$ Biol Chem 1985; 260: 12160-12166.

32. Barton AJL, Harrison PJ, Najlerahim A, et al. Increased tau messenger RNA in Alzheimer's disease hippocampus. Am J Pathol 1990; 137: 497-502.

33. Buell SJ, Coleman PD. Dendritic growth in the aged human brain and failure of growth in senile dementia. Science 1979; 206: 854-856.

34. Reuter F, Giarre M, Farah J, et al. Dependence of position-effect variegation in Drosophila on dose of a gene encoding an unusual zinc-finger protein. Nature 1990; 344: 219-223.

35. Ristiniemi J, Oikarinen J. Homology of histone $\mathrm{Hl}$ variants with adenine nucleotide-binding proteins. Biochem Biophys Res Comm 1988; 153: 783-79l.
36. Walker PR, LeBlanc J,Sikorska M. Effects of aluminum and other cations on the structure of brain and liver chromatin. Biochemistry 1989; 28: 2911-2915.

37. Parhad IM, Krekoski CA, Mathew A, Tran PM. Neuronal gene expression in aluminum myelopathy. Cell and Mol Neurobiol 1989; 9: 123-138.

38. Goldstein ME, Weiss SR, Lazzarini RA, et al. mRNA levels of all three neurofilament proteins decline following nerve transection. Mol Brain Res 1988; 3: 287-292.

39. Rosenfeld J, Dorman ME, Griffin JW, et al. Distribution of neurofilament antigens after axonal injury. J Neuropathol Exp Neurol 1987; 46: 269-282.

40. Schlaepfer WW, Bruce J (1990); Simultaneous up-regulation of neurofilament proteins during the postnatal development of the rat nervous system. J Neurosci Res 25: 39-49. 